\title{
Comparison between Two Genera, Species and Cultivars in Lactuceae \\ I. Karyotype analysis
}

M. Z. Haque and M. B. E. Godward

School of Biological Sciences, Queen Mary College,

London EI 4NS, Great Britain

Accepted July 5, 1984

Karyotype analysis was carried out prior to later investigations on dose tolerance, and characters of the pollen grains and carpopodium using the scanning electron microscope. So far as is known, no previous karyotype analysis has been carried out on the three cultivars of Lactuca sativa.

\section{Materials and methods}

Karyotype analysis was carried out on somatic root tip metaphases of the three cultivars of Lactuca sativa, Webb's Wonderful, Lobjoit's Green Cos and Tom Thumb, Lactuca serriola collected from Essex, and a cultivar of Cichorium intybus, Witloof Chicory.

Seeds were germinated on moist filter paper at $19-22^{\circ} \mathrm{C}$. Actively growing root tips of 3-4 mm in length were pretreated with $0.002 \mathrm{M}$ solution of 8-Hydroxyquinoline for $3 \frac{1}{2}$ to 4 hours at $14-16^{\circ} \mathrm{C}$. After the pretreatment the root tips were thoroughly washed with distilled water and fixed in acetic-alcohol $(1: 3)$.

The root tips were hydrolysed in $1 \mathrm{~N} \mathrm{Hydrochloric} \mathrm{acid} \mathrm{at} 60^{\circ} \mathrm{C}$ for 10 minutes and stained in Feulgen's solution for 20 to 40 minutes. Squashes were made in a drop of aceto-carmine. Slides were sealed with rubber solution and examined for suitable metaphases. Fifteen to twenty metaphases with well separated chromosomes were photographed for each cultivar and L. serriola. The magnification of the negative was $\times 1760$, and the prints were enlarged $\times 3$, giving a total magnification on the prints of $\times 5280$. Using these prints, chromosomes were cut from single metaphase plates (Figs. 3a, 3b, 4a, 4b, 7a, 7b, 9a, 9b, 11a and 11b) and arranged in pairs, as far as possible according to homology and in order of decreasing length (Figs. 1a, 1b, 2a, 2b, 5a, 5b, 6a, 6b, 10a and 10b.)

Measurements were taken from the prints, in $\mathrm{mm}$, later converted to $\mu \mathrm{m}$, and the mean lengths, with standard deviations, and ranges, tabulated for each cultivar and species (Table 1). In addition, arm ratios were calculated and similarly tabulated (Table 2). The four N.O. chromosomes of $L$. sativa cultivars and $L$. serriola (see karyotypes and Figs. 1a-9b) could be recognised. The N.O. regions were subject to variable degrees of residual expansion at metaphase (or premetaphase). The data on lengths of N.O. regions and dimensions of the satellites are also tabulated (Table 3). 

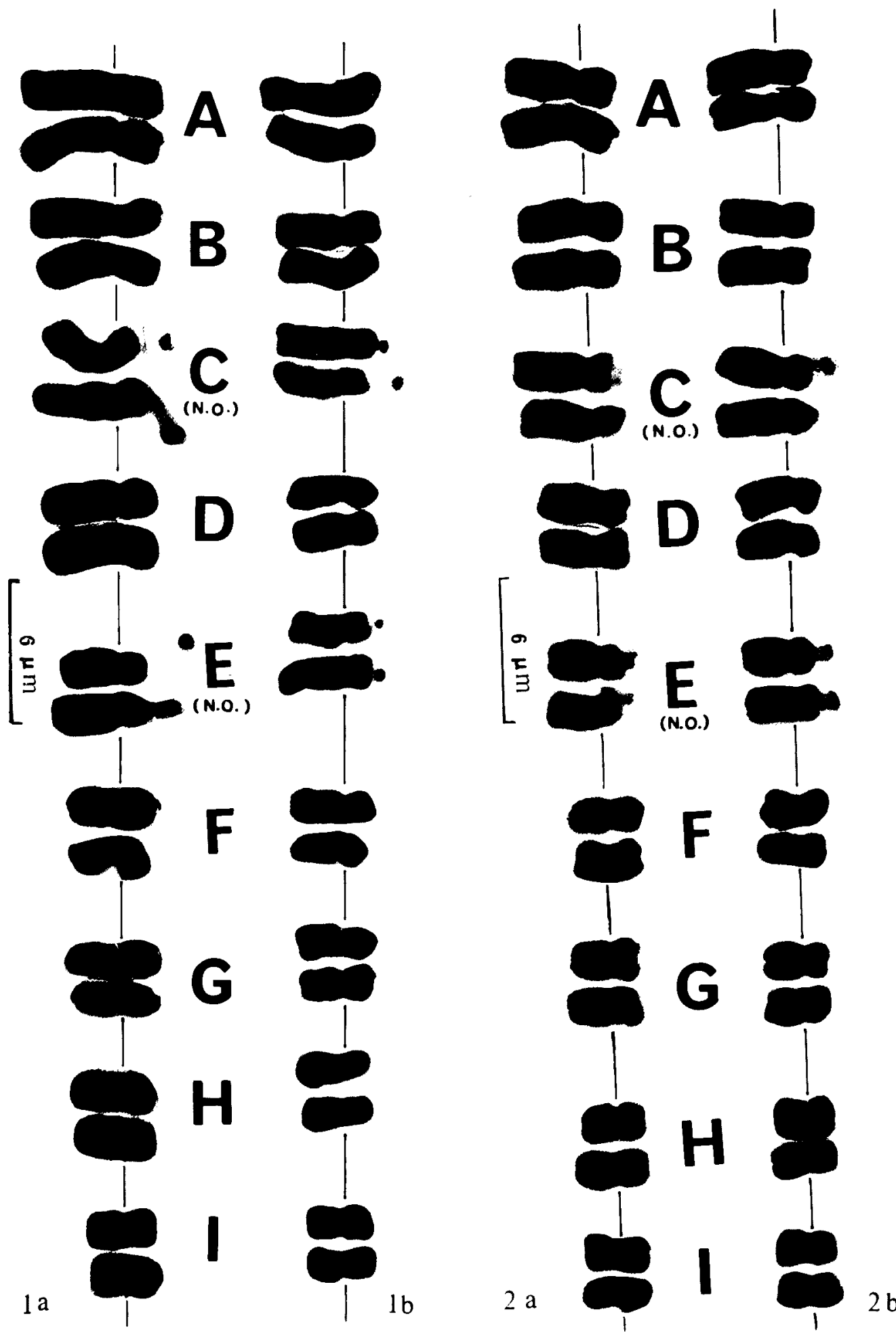

Figs. 1, 2, 5, 6 and 10. Chromosomes of the karyotypes in order of decreasing length. Each pair of homologues is designated by a letter (A, B etc.). N. O.=nucleolar-organising chromosomes. $1 \mathrm{a}$ and $1 \mathrm{~b}$, karyotype of $L$. sativa cultivar Lobjoit's Green Cos represented by two metaphases a and b. $2 \mathrm{a}$ and $2 \mathrm{~b}$, karyotype of $L$. sativa cultivar Webb's Wonderful represented by two metaphases $a$ and $b$. 


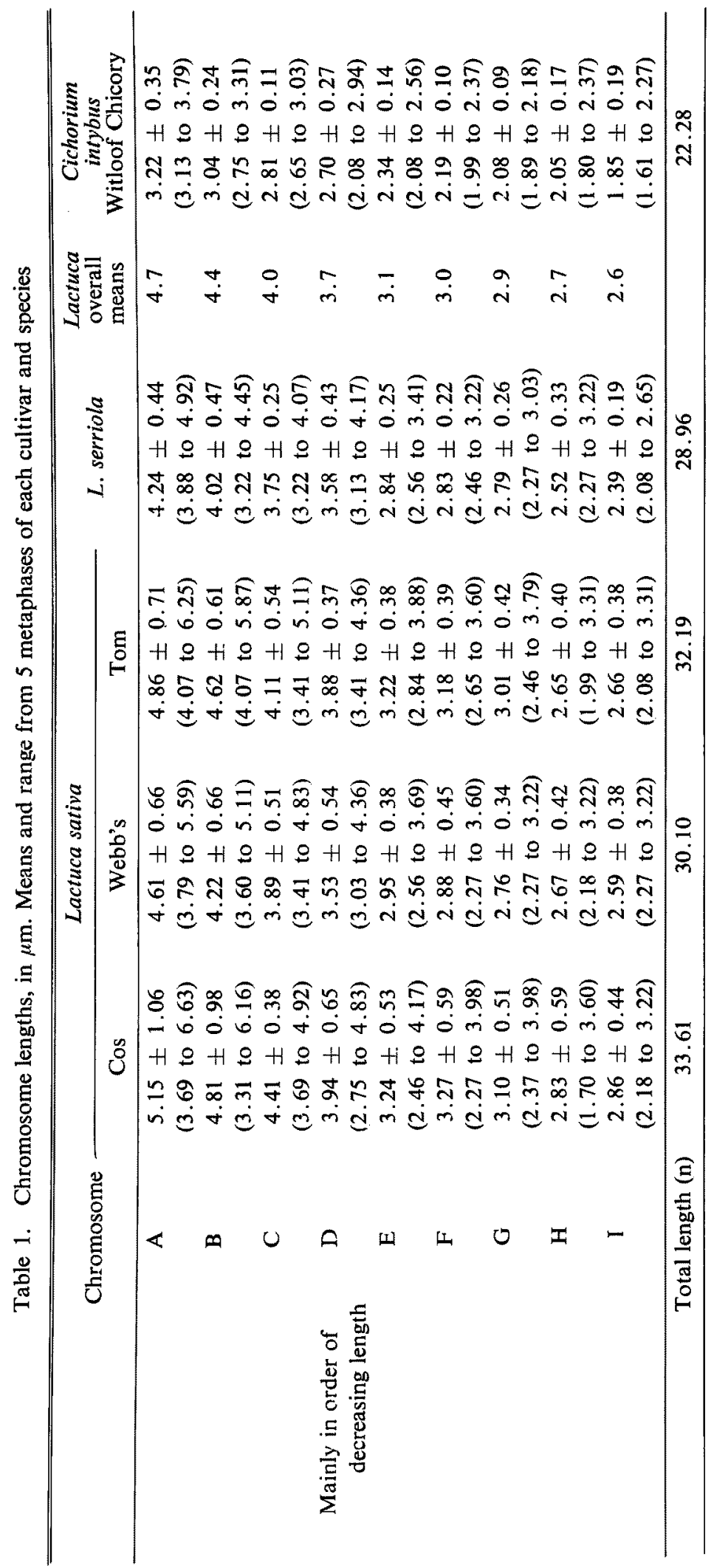




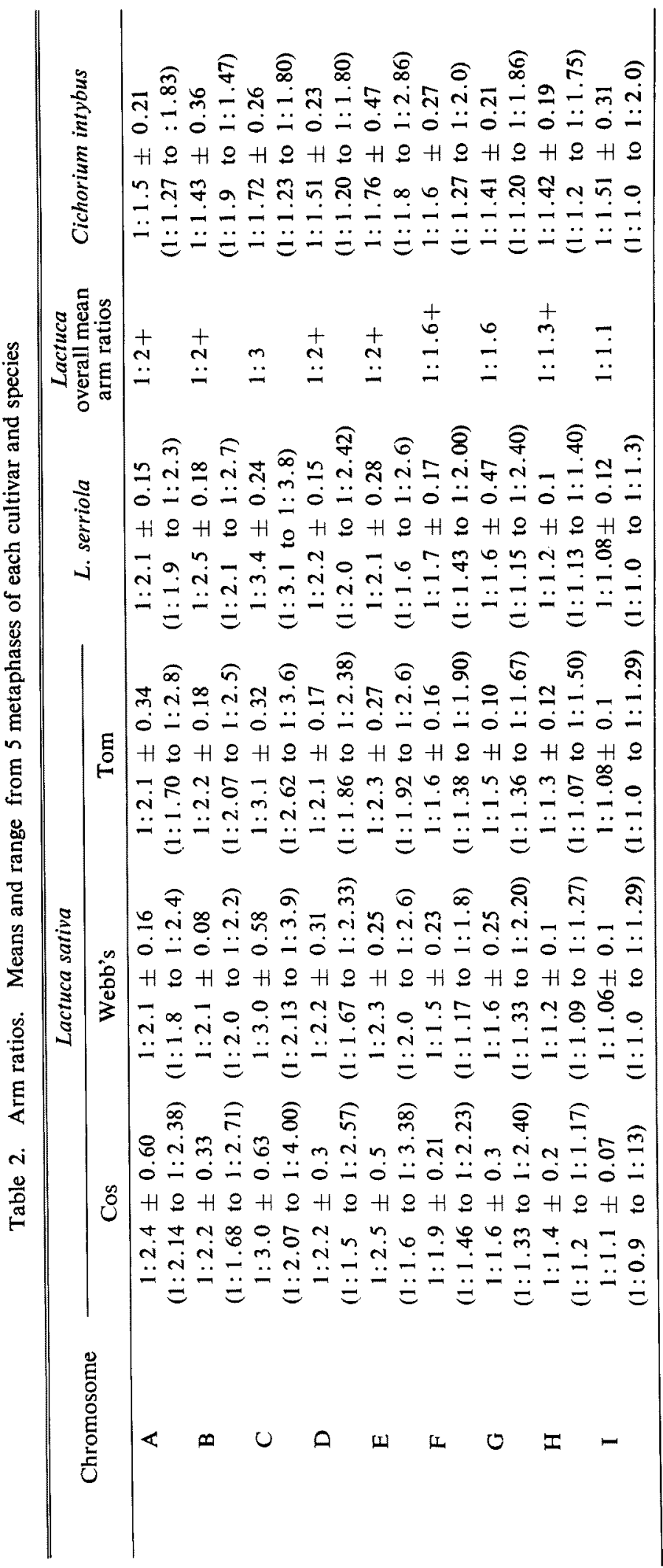




\section{Results}

In Lactuca, no pronounced difference appears at first glance between the three cultivars and L. serriola, in the morphology of the somatic chromosomes of the root tip (Figs. 1a, 1b, 2a, 2b, 5a, 5b, 6a and 6b and Tables 1-3). The chromosomes of Cos are however the longest (Table 1) followed by Tom, Webb's and L. serriola.

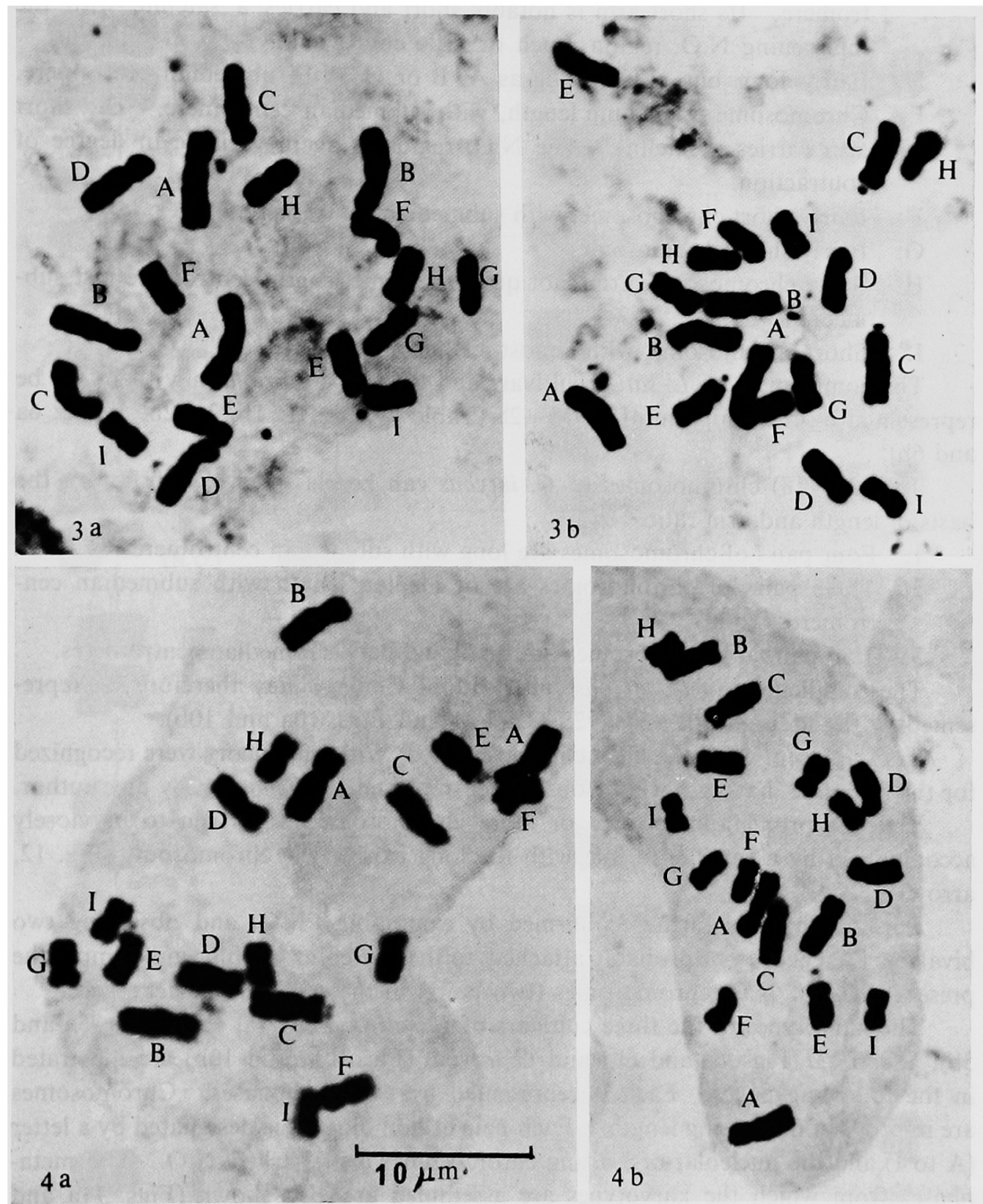

Figs. 3-4. 3a and $3 b$, somatic metaphases of Cos with $2 n=18$, showing all 4 satellited chromosomes (Lettered as in karyotype, Figs. 1a and 1b). Bar representing $10 \mu \mathrm{m}$ applies to Figs. 3a, 3b, 4a and $4 \mathrm{~b} . \quad \times 2700$. $4 \mathrm{a}$ and $4 \mathrm{~b}$, somatic metaphases of Webb's with $2 \mathrm{n}=18$, showing 3 of the 4 satellited chomosomes (Lettered as in karyotype, Figs. 2a and 2b). $\times 2700$. 
The $2 n=18$ chromosomes can be identified and grouped on the basis of length (Table 1), arm ratios (Table 2) and presence or absence of a secondary constriction (Table 3) as follows:

A. Long chromosome with submedian centromere.

B. "

but not as long as $\mathrm{A}$ and $\mathrm{B}$, with subterminal centromere. Its short arm is notably short and carries a satellite with the intervening N.O. region much or little contracted.

D. Fairly long but not as long as A, B or C, with submedian centromere.

E. Chromosome of medium length, with submedian centromere. The short arm carries a satellite. The N.O. region is again variable in degree of contraction.

F. Fairly short chromosome, with submedian centromere.

G. Fairly short chromosome, " "

H. Short chromosome, arms not quite the same length, centromere just submedian.

I. Short chromosome, with almost median centromere.

The complement of $L$. sativa cultivars and that of $L$. serriola may therefore be represented by the idiogram $4 L+3 M+2 S$ (Table 1, Figs. 1a, 1b, 2a, 2b, 5a, 5b, 6a and $6 \mathrm{~b}$ ).

The $(2 \mathrm{n}=18)$ chromosomes of $C$. intybus can be classified as follows on the basis of length and arm ratios:

1. Four pairs of chromosomes are long with submedian centromeres.

2. Three pairs of chromosomes are of median length with submedian centromeres.

3. Two pairs of chromosomes are small and have submedian centromeres.

The complement of $C$. intybus cult. Witloof Chicory may therefore be represented by the idogram $4 \mathrm{~L}+3 \mathrm{M}+2 \mathrm{~S}$ (Table 1 and Figs. 10a and 10b).

In the present work the N.O. chromosomes of Witloof Chicory were recognized for the first time, having not previously been reported in Cichorium by any author.

In three prometaphases one or more chromosomes were seen to be closely accompanied by a satellite in line with the long axis of the chromosome (Fig. 12, arrow).

This finding was further confirmed by examining PMCs and observing two bivalents attached to, or probably attached, to the nucleolus. This would imply the presence of four N.O. chromosomes (two pairs) in the somatic prometaphase.

The karyotypes of the three cultivars of L. sativa (Figs. 1a, 1b, 2a, 2b, 5a and 5b), L. serriola (Figs. 6a and 6b) and C. intybus (Figs. 10a and 10b) are illustrated in the following pages. Each is represented by two metaphases. Chromosomes are in order of decreasing length. Each pair of homologues is designated by a letter (A to I) and the nucleolar-organising chromosomes also marked N.O. The metaphases from which the karyotypes are assembled are also shown (Figs. 11a and $11 \mathrm{~b})$.

Figs. 5-6. 5a and 5b, karyotype of $L$. sativa cultivar Tom Thumb represented by two metaphases $a$ and $b$. $6 a$ and $6 b$, karyotype of Lactuca serriola represented by two metaphases a and $b$. 


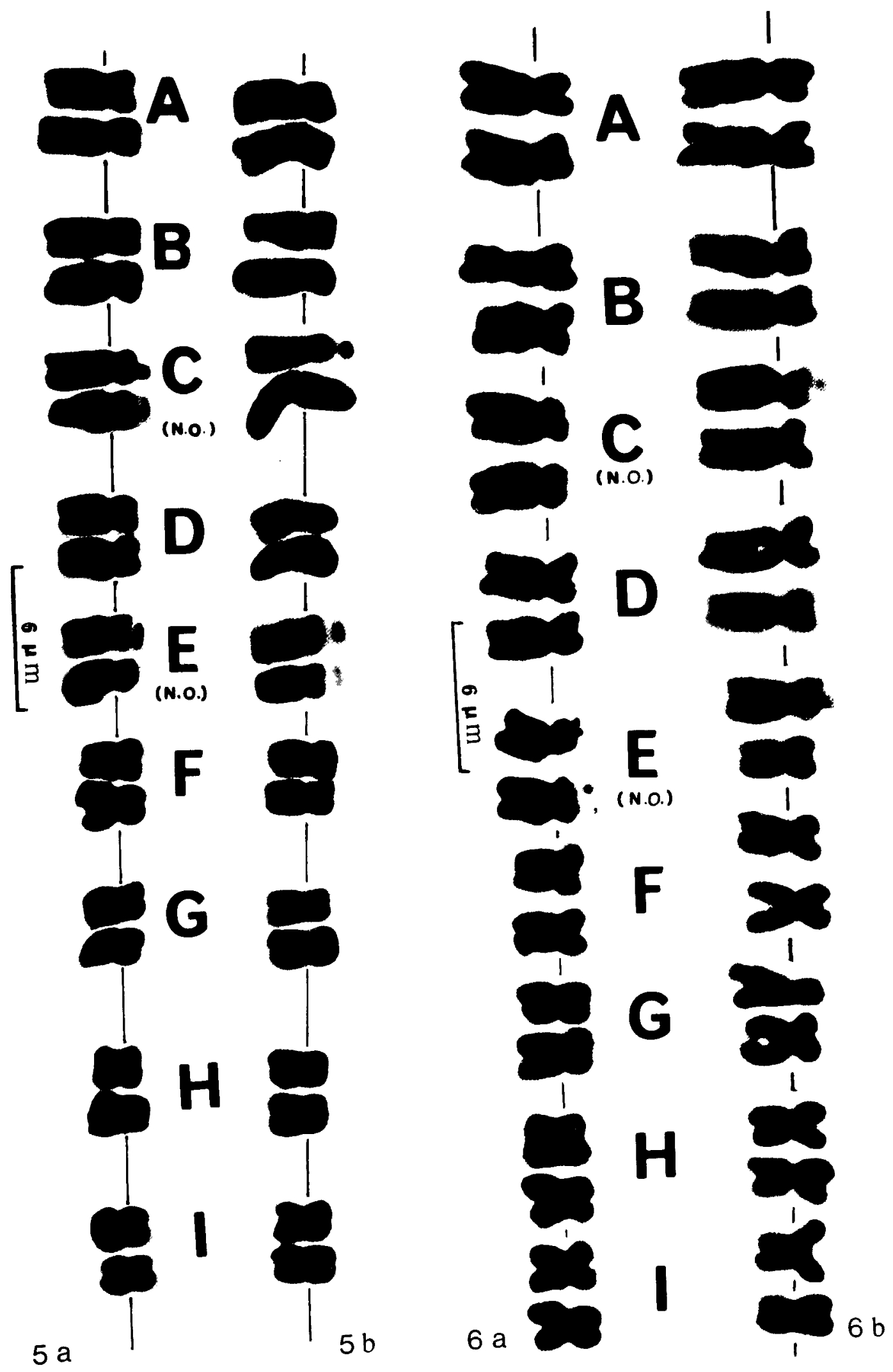




\section{Discussion}

\section{i. Length and arm ratios}

The chromosomes of $C$. intybus are shorter than those of Lactuca.

When the chromosomes of the four representatives of Lactuca, L. sativa cultivars and $L$. serriola are compared, the remarkable similarity between the cultivars

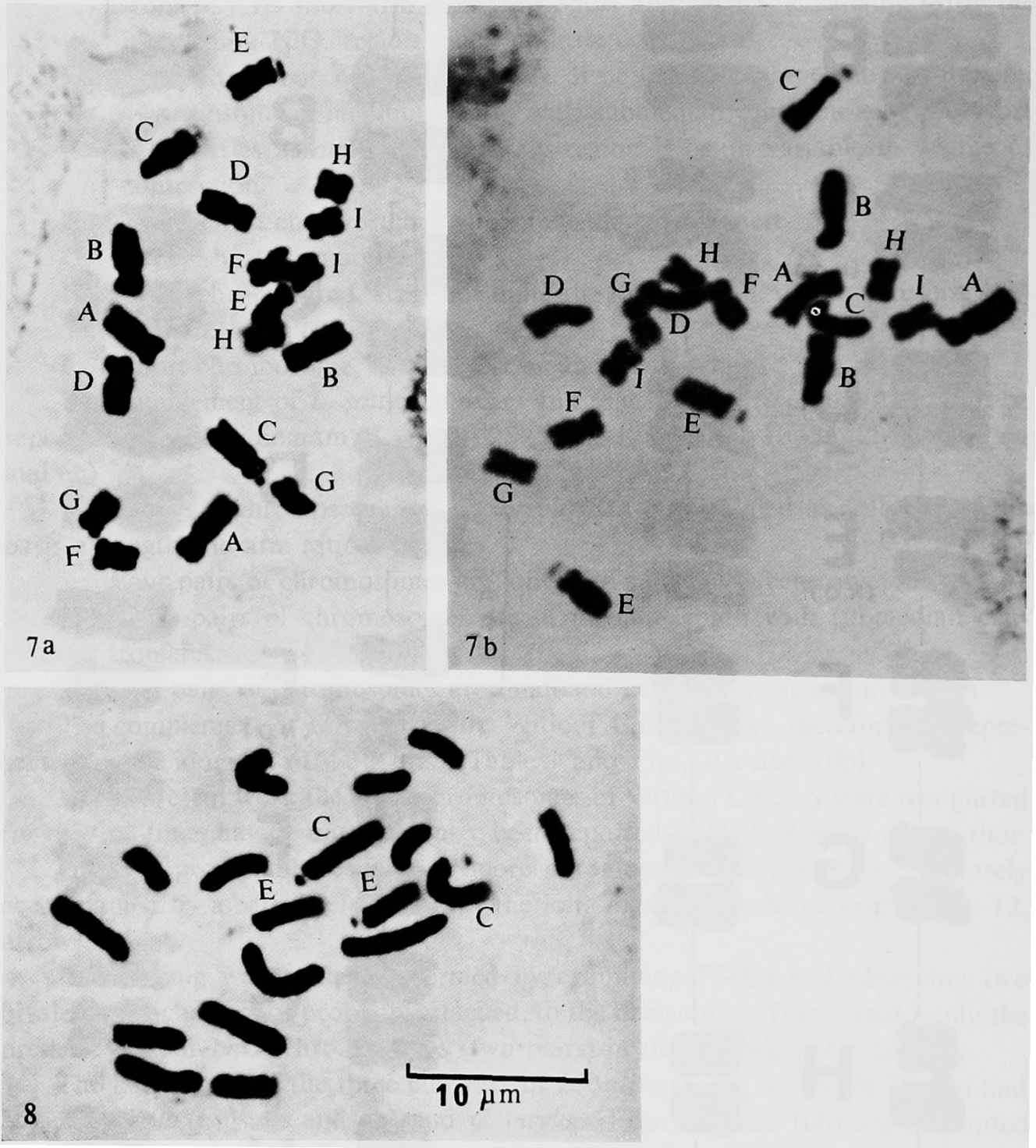

Figs. 7-8. 7a, somatic metaphase of Tom Thumb with $2 n=18$, showing 3 of the 4 satellited chromosome (Lettered as in karyotype Figs. 5a and 5b). Bar representing $10 \mu \mathrm{m}$ applies to Figs. 7a, $7 \mathrm{~b}$ and 8 . $\times 2700,7 \mathrm{~b}$ and 8 , somatic metaphase of Tom Thumb with $2 \mathrm{n}=18$, showing all the 4 satellited chromosomes (Lettered in $7 \mathrm{~b}$ as in karyotype Figs. $5 \mathrm{a}$ and $5 \mathrm{~b}$ ). $\quad \times 2700$.

Figs. 9a and 9b. Somatic metaphase of $L$. serriola, showing at least 3 perhaps all 4 of the satellited chromosomes (Lettered as in karyotype Figs. $6 \mathrm{a}$ and $6 \mathrm{~b}$ ). Bar representing $10 \mu \mathrm{m}$ applies to both 


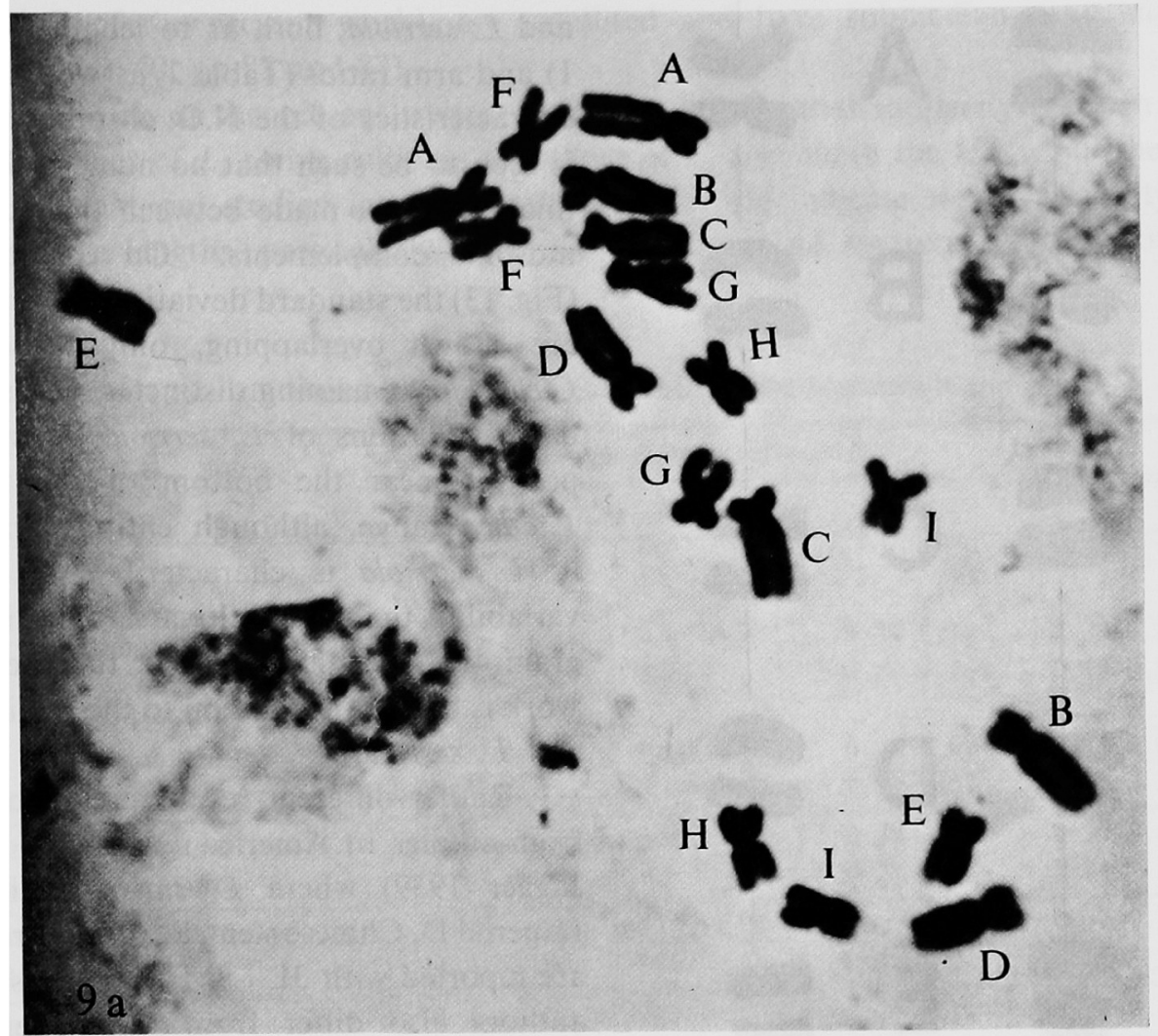

$\mathrm{H}$

$$
10 \mu \mathrm{m}
$$

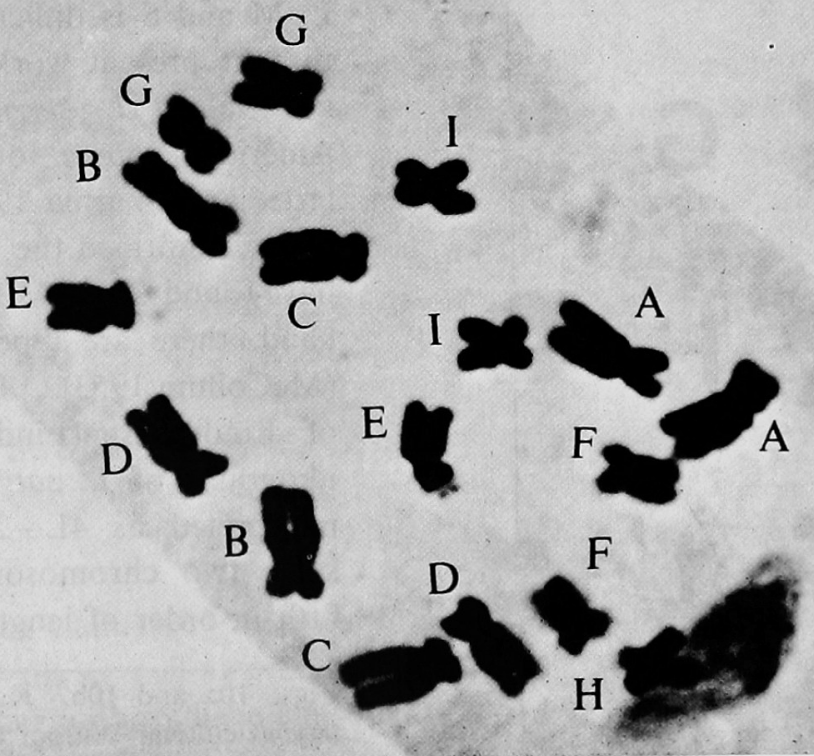




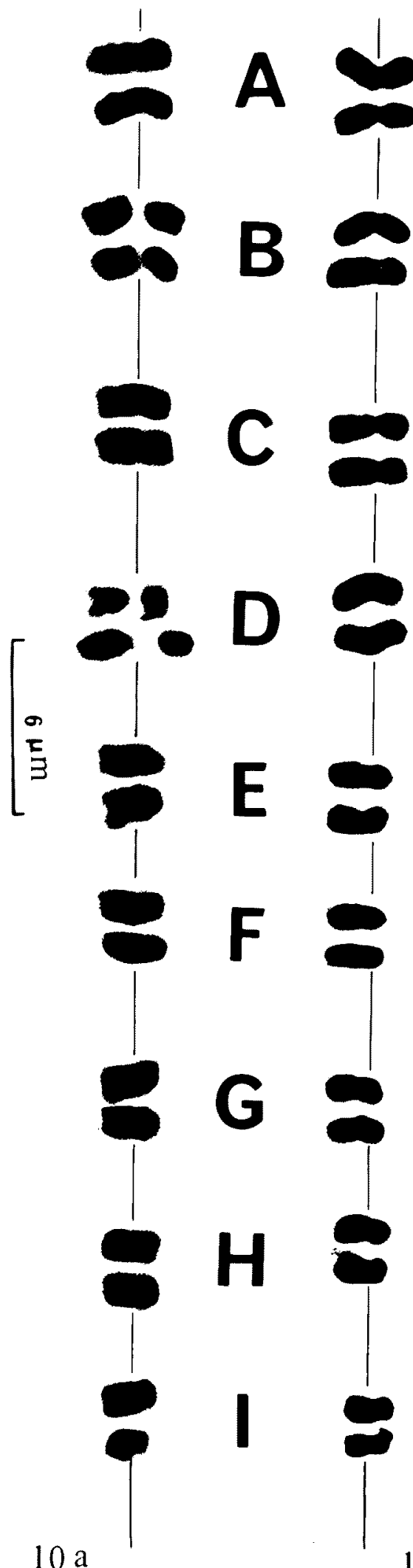

and $L$. serriola, both as to length (Table 1) and arm ratios (Table 2) as well as the characteristics of the N.O. chromosomes, is seen to be such that no numerical distinction can be made between their chromosome complements. On the graph (Fig. 13) the standard deviations of lengths are shown overlapping, only those of Cichorium remaining distinct. The standard deviations of $L$. serriola occupy a position near the bottom of the total Lactuca range, although entirely within it; $L$. serriola is characterised by less variability than the cultivars. The idiogram $4 \mathrm{~L}+3 \mathrm{M}+2 \mathrm{~S}$ found in the present work is therefore common to the cultivars and $L$. serriola.

Rather different results are reported from studies in America (Whitaker and Jagger 1939) where L. sativa cultivars Imperial D, Chinese stem, Bavarian Brown are reported with $3 \mathrm{~L}+3 \mathrm{M}+3 \mathrm{~S}$; the same authors also differ from the writer in finding $4 \mathrm{~L}+2 \mathrm{M}+3 \mathrm{~S}$ in $L$. serriola var. integrata from California and in $L$. serriola material from the U.S.S.R. No detailed measurements are given, and no arm ratios, so that the significance of their $\mathrm{L}, \mathrm{M}$ and $\mathrm{S}$ is difficult to compare with that in present work. Curiously, using material of $L$. serriola from the same American source, other authors (Chatterjee and Sharma 1969), have not apparently confirmed the above idiogram but have found $2 L+4 M+3 S$. On the other hand, there are reports of $4 \mathrm{~L}+2 \mathrm{M}+3 \mathrm{~S}$ (McCollum 1953). The detailed account of Lindquvist (Lindqvist 1960) shows idiograms of $L$. sativa which would be interpreted as $4 \mathrm{~L}+2 \mathrm{M}+3 \mathrm{~S}$, while the same two chromosomes (i.e. third and fifth in order of length, corresponding to

Figs. 10a and 10b. Karyotype of Cichorium intybus cultivar Witloof Chicory represented by two metaphases $a$ and $b . \quad \times 2700$. 
$\mathrm{C}$ and $\mathrm{E}$ of the present work), are satellited and have submedian centromeres (Lindqvist 1960, pp 83 and 84).

The work of the present writers indicates the essential similarity between the chromosomes of L. sativa cultivars and those of L. serriola in the U.K., but the reports on material studied in other parts of the world indicate some variability in chromosme lengths, particularly as regards the long and medium length chromosomes.

Table 3. Expansion of N.O. region and satellite diameters in $\mu \mathrm{m}$

\begin{tabular}{|c|c|c|c|c|c|}
\hline \multirow{2}{*}{ Chromosome } & & \multicolumn{3}{|c|}{ Lactuca sativa cultivars } & \multirow{2}{*}{ L. serriola } \\
\hline & & $\operatorname{Cos}$ & Webb's & Tom & \\
\hline \multicolumn{6}{|l|}{ N. O. region: } \\
\hline Homologue & 1 & $0.09-2.08$ & $0.09-0.47$ & $0.09-1.14$ & $0.09-0.28$ \\
\hline E & 2 & $0.09-1.70^{*}$ & 0.09 & $0.09-0.76^{*}$ & $0.15-0.28$ \\
\hline Homologue & 1 & $0.09-1.04$ & $0.06-0.66$ & $0.09-0.09$ & $0.04-0.28$ \\
\hline$" \prime$ & 2 & $0.09-0.85$ & $0.09-0.38$ & $0.13-0.57$ & $0.04-0.28$ \\
\hline $\begin{array}{l}\text { Satellites diameters } \\
\text { separately measured }\end{array}$ & $\begin{array}{r}\mathrm{C} 1 \\
2\end{array}$ & $\begin{array}{l}0.47- \\
0.47-\end{array}$ & $0.38-0.47$ & $\begin{array}{l}0.38- \\
0.38-0.47\end{array}$ & $\begin{array}{l}0.39-0.47 \\
0.44\end{array}$ \\
\hline $\begin{array}{l}\text { Diameter of fused } \\
\text { satellites }\end{array}$ & $\begin{array}{l}1 \\
2\end{array}$ & $\begin{array}{l}0.57-0.85 \\
0.76-0.85\end{array}$ & $\begin{array}{l}0.57-0.66 \\
0.57-0.76\end{array}$ & $\begin{array}{l}0.66-0.76 \\
0.57-0.76\end{array}$ & $\begin{array}{l}0.57-0.76 \\
0.66-\end{array}$ \\
\hline $\begin{array}{l}\text { Satellites diameters } \\
\text { separately measured }\end{array}$ & $\begin{array}{r}\mathrm{E} 1 \\
2\end{array}$ & $\begin{array}{l}0.38-0.47 \\
0.47-\end{array}$ & $\begin{array}{l}0.47- \\
0.38-\end{array}$ & $\begin{array}{l}0.38-0.57 \\
0.47-\end{array}$ & $\begin{array}{l}0.38-0.47 \\
0.38-0.47\end{array}$ \\
\hline $\begin{array}{l}\text { Diameter of fused } \\
\text { satellites }\end{array}$ & $\begin{array}{l}1 \\
2\end{array}$ & $\begin{array}{l}0.66-0.76 \\
0.57-0.76\end{array}$ & $\begin{array}{l}0.57-0.76 \\
0.66-0.76\end{array}$ & $\begin{array}{l}0.57-0.76 \\
0.57-0.76\end{array}$ & $\begin{array}{l}0.57-0.66 \\
0.76\end{array}$ \\
\hline
\end{tabular}

* indicates very wide range.

\section{ii. N.O. chromosomes}

In the present work, the difference between varieties in respect of their N.O. chromosomes (Table 3 ) are only that the N.O. region of chromosome C is seen more expanded in Cos and Tom than in Webbs and L. serriola. The diameters of the satellites are identical throughout the three cultivars and $L$. serriola, although they are sometimes seen separately as one on each chromatid (Fig. 6a) and sometimes these are so close as to appear fused (Fig. 8). This may be the basis of size differences in different cultivars and species found by a previous author (Lindquist 1960 , p. 84).

It is of interest that both Lactuca and Cichorium have two pairs of N.O. chromosomes, of which one pair is long and the other is short.

\section{Chicory}

The present work claims only that there are 18 chromosomes, on the basis of formation of 9 bivalents as well as presence of 18 chromosomes in somatic mitosis in the root tip. Other authors have claimed the presence of $\mathbf{B}$ chromosomes, and a diploid chromosome number of 20 (Javorciková 1970, Feráková and Javorciková 
1970). In the opinion of the writers the chromosomes of Cichorium are liable to break through the centromere during preparation of the slide by the squash technique; a short arm broken off will convey the impression of a B chromosome and also increased chromosome number. This occurrence has been found several times in the writers' material (Fig. 11a).

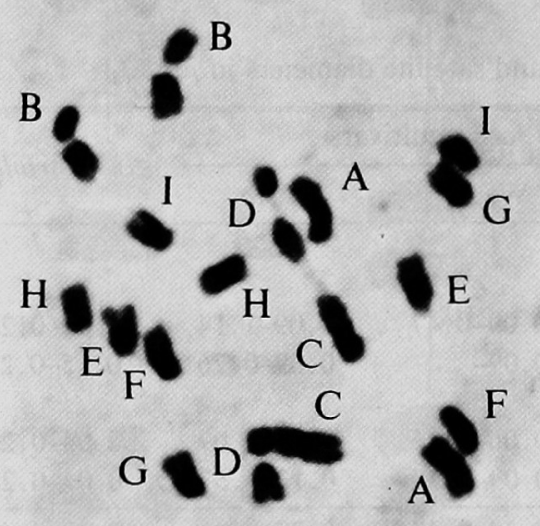

$11 \mathrm{a}$

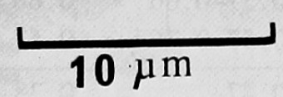

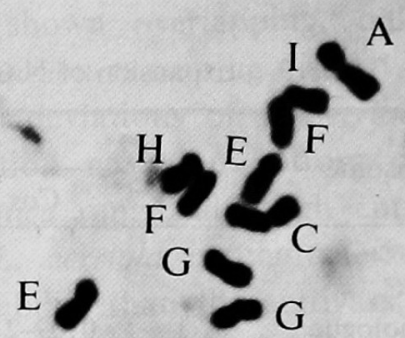

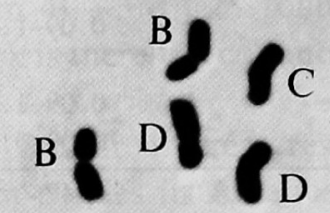

$11 \mathrm{~b}$

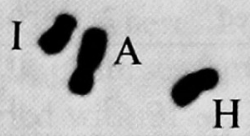

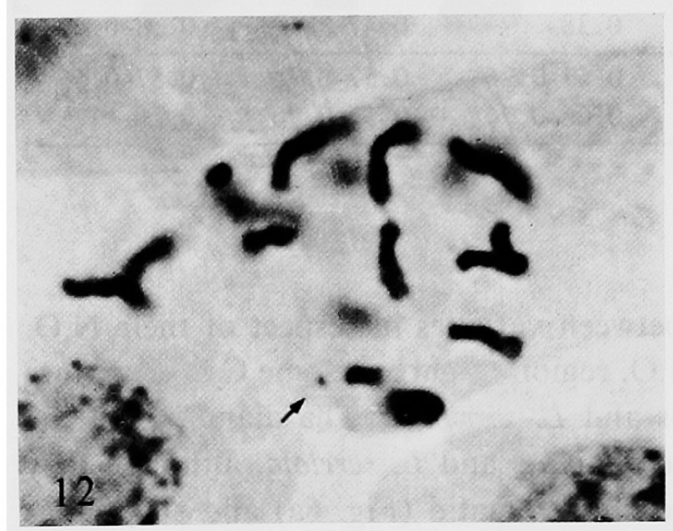

Figs. 11-12. 11a and $11 \mathrm{~b}$, somatic metaphases of $C$. intybus with $2 \mathrm{n}=18$ chromosomes (Lettered as in karyotype Figs. 10a and 10b). Bar representing $10 \mu \mathrm{m}$ applies to Figs. 11a, 11b and 12. $\times 2700$. 12 , somatic prometaphase of $C$. intybus clearly showing one of the satellited chromosomes (arrow). $\times 2700$.

The number of N.O. chromosomes present in Cichorium has been established as four by the present authors, on the evidence that two bivalents are attached to the nucleolus at diakinesis.

A reliable count of four N.O. chromosomes in somatic mitosis has not however been possible. It may be that the tendency for the satellite to become detached, as sometimes happens in Lactuca, is even more marked in Cichorium and this is 
responsible for the difficulties of finding all four N.O. chromosomes. The nonrecognition of any N.O. chromosomes by previous workers may be due to the same cause.

All the chromosomes of Cichorium were found in the present work to have submedian centromeres, and this is confirmed by the idiograms (Figs. 2 and 3 Dujardin et al. 1979) in a recent publication (although the authors state that 5 are median!). Another account (Ricci 1964) refers to the centromeres as submedian or subterminal except for one pair with median centromeres in the "typical form" of $C$. intybus, and two pairs with median centromeres in a sub-species.

\section{RELATIVE CHROMOSOME LENGTHS}
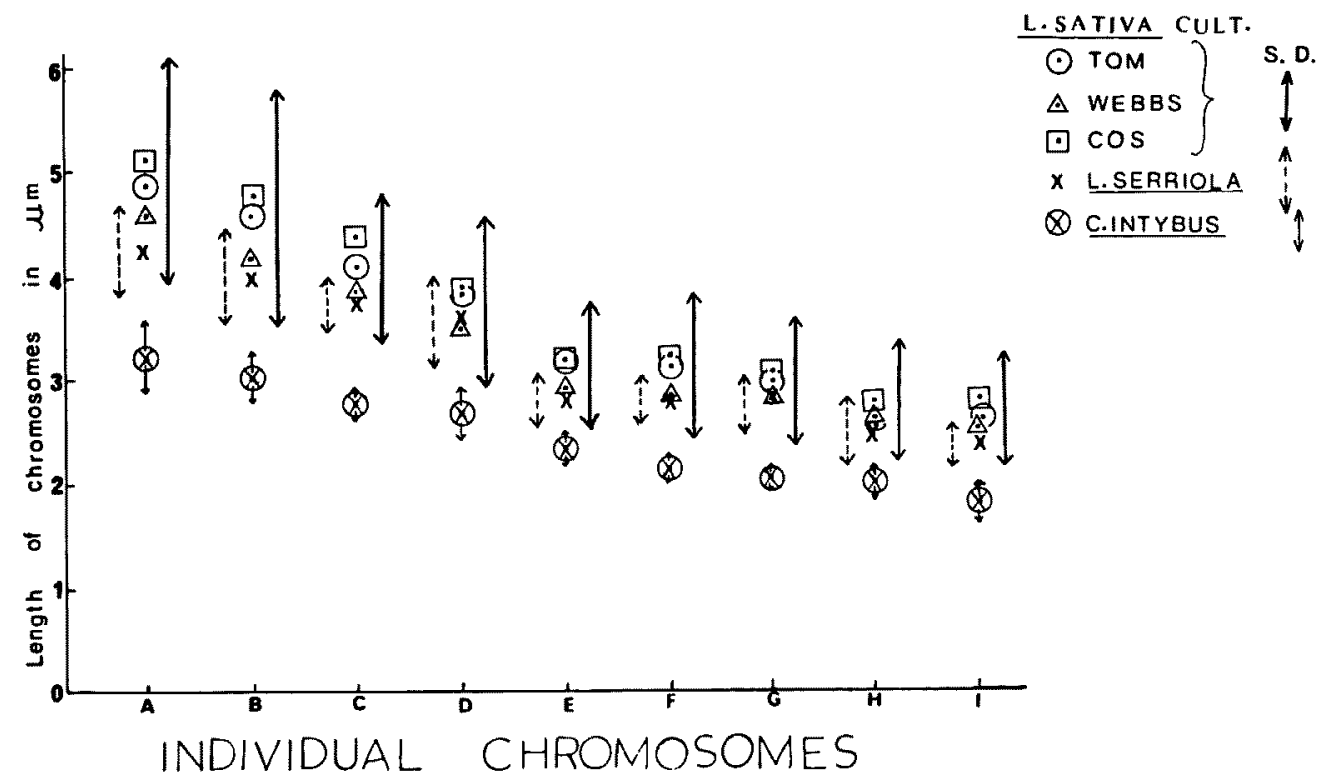

Fig. 13. Means and standard deviations of chromosome lengths in L. sativa cultivars, L. serriola and C. intybus. For identification of individual chomosomes see Figs. 1, 2, 5, 6 and 10.

On balance it does not seem likely that much chromosomal variation in $C$. intybus has been found.

iii. Chromosome number

Chromosome counts of $2 \mathrm{n}=18$ were observed in all three cultivars of $L$. sativa and $L$. serriola. This is the first determination for the cultivars Cos, Tom and Webb's. However the chromosome number $(2 n=18)$ of $L$. serriola has been frequently reported (Löve and Löve 1961, Moore 1973, 1974, 1977, Tomb et al. 1978).

The most detailed study is that of Lindqvist (1960), which will be discussed later (Haque and Godward 1984) in relation to meiosis.

Chromosome counts of $2 \mathrm{n}=18$ for $L$. sativa and $C$. intybus have been reported by several authors (Löve and Löve 1961, Moore 1973, 1974, 1977, Tomb et al. 1978). 


\section{Summary}

Karyotypes of three cultivars of Lactuca sativa (Webb's Wonderful, Lobjoit's Green Cos and Tom Thumb), Lactuca serriola collected from the field in the county of Essex, U.K. and a cultivar of Cichorium intybus (Witloof Chicory), were analysed in detail so that essential comparative information was available for use in later studies (Haque and Godward, Papers II, III and IV). Statistical data on chromosome lengths and centromere positions, together with the recognition of the nucleolar-organising chromosomes, enabled the nine chromosomes of the haploid sets to be recognised individually, and these were designated A, B, C, D, E, F, G, H and $\mathrm{I}, \mathrm{C}$ and $\mathrm{E}$ being the nucleolar organising chromosomes, these being recognised in $C$. intybus for the first time. There were slight differences in chromosome lengths, the Lactuca sativa cultivars and $L$. serriola being distinguishable by their mean lengths, but only those of $C$. intybus were significantly smaller. Comparisons with the previously published data on Lactuca and Cichorium are made.

\section{Bibliography}

Chatterjee, T. and Sharma, A. K. 1969. Cytotaxonomy of Cichorieae. Genetics 40: 577-590.

Dujardin, M., Louant, B. P. et Tilquin, J. P. 1979. Determination du caryogramme de Cichorium intybus L. Ann. Amelior. Plants 29: 305-310.

Feráková, V. and Javorciková, D. 1970. In: Majovsky, J. et al. 1970. "Index of chromosome numbers of Slovakian flora, Part 2". Acta Fac. Rerum Nat. Univ. Comenianae. Bot. 18: $45-60$.

Haque, M. Z. and Godward, M. B. E. 1984. Effects of seed-irradiation on meiosis in $M_{1}$ plants of Lactuca and related plants. Genetica 65 : 179-186.

- and - Comparison between two genera, species and cultivars in Lactuceae, Paper II. Effects of seed-irradiation on chiasma frequency. Cytologia. (in press)

- and - Comparison between two genera, species and cultivars in Lactuceae, Paper III. DNA amount and radiosensitivity. Cytologia. (in press)

- and -. Comparison between two genera, species and cultivars in Lactuceae, Paper IV. Effects of seed-irradiation on mitosis. Cytologia. (in press)

Javorciková, D. 1970. B-chromosomes in Cichorium intybus L. from Slovak localities. Acta Fac. Rerum Nat. Univ. Comenianae Bot. 16: 73-76.

Lindqvist, K. 1960. Cytogenetic studies in the serriola group of Lactuca. Hereditas 46: 815.

Löve, A. and Löve, D. 1961. Chromosome numbers of Central and Northwest European plant species. Opera Botanica. A. Societate Botanica. Lundensi Lund. 5: p. 581.

McCollum, G. D. 1953. Cytogenetic relationships of Lactuca serriola and L. sativa-M. S. Thesis. Washington State University.

Moore, R. J. ed. 1973. Index to Plant Chromosome Numbers for 1967-1971. International Bureau for Plant Taxonomy and Nomenclature. Utrecht, Netherlands.

- 1974. Index to Plant Chromosome Numbers for 1972. International Bureau for Plant Taxonomy and Nomenclature. Utrecht, Netherlands.

- 1977. Index to Plant Chromosome Numbers for 1973-974. International Bureau for Plant Taxonomy and Nomenclature. Utrecht, Netherlands.

Ricci, I. 1964. Cichorium intybus L. subsp. Spicatum subsp. Nova Studio citotassonomico. Annali di Botanica 28 : 219-223.

Tomb, A. S., Chambers, K. L., Kyhos, D. W., Powell, A. M. and Raven, P. H. 1978. Chromosome numbers in the Compositae XIV. Lactuceae. Am. J. Bot. 65: 717-721.

Whitaker, T. W. and Jagger, I. C. 1939. Cytogenetic observations in Lactuca. J. Agr. Res., Washington 58: 297-306. 